\title{
RISCOS E EFEITOS TERRITORIAIS NA IMPLANTAÇÃO DE EMPREENDIMENTOS AGROINDUSTRIAIS CANAVIEIROS
}

\author{
Eduardo Rozetti de Carvalho ${ }^{1}$ \\ Vicente de Paulo da Silva ${ }^{2}$
}

Resumo: O espaço rural passa por modificações motivadas pelo desenvolvimento, que ultrapassam os limites territoriais, sociais e ambientais, gerando diferentes riscos as suas estruturas de representação por meio de conflitualidades: de um lado o capital e do outro os afetados. Pensando nesses fatores, apresenta-se como objetivo principal desse artigo a busca de compreender como ocorre a formação do agronegócio canavieiro, destacando os riscos que se seguem a partir dessa opção. Dá-se especial atenção à perspectiva dos efeitos gerados no processo do setor na contemporaneidade. Metodologicamente esse artigo está sustentado em debates e revisões acerca da temática, bem como direcionamentos reflexivos das territorialidades (re)criadas atendendo e/ou resistindo a esse agronegócio. Como resultados parciais tem-se o entendimento que o capital é responsável por gerar efeitos que ultrapassam aspectos apenas ligados ao trabalho, mas transformam fatores tais como: os modos de vida, a segurança/soberania alimentar e ambiental. Ligado a isso, destaca-se a categoria território como válida para compreender esses processos, pois a ele são englobadas as relações de poder e de territorialidades distintas. Por fim, apresentam-se também reflexões sobre a relação do capital canavieiro, modelando o território, $e$ os riscos social, ambiental e econômico, que se tornam presentes quando da implantação desses grandes empreendimentos.

Palavras-chave: Empreendimentos Sucroalcooleiros; Território; Riscos; Canavieiro.

\section{Risks and effects on territory deployment of sugarcane enterprises agribusiness}

\begin{abstract}
The countryside undergoes modifications motivated by the development, beyond the territory, society and environmental limits, generating different risks their representation structures by conflictualities: on one hand the capital and other affected. Thinking about these factors is presented as the main objective of this paper seeks to understand how the formation of the sugarcane agribusiness occurs, highlighting the following risks from this option. Gives particular attention to the perspective of the effects generated in the process industry nowadays. Methodologically this article is supported in discussions and revisions on the theme, as well as reflective directions of territoriality (re)created view and / or resisting this agribusiness. As partial results has been the understanding that finance is responsible for generating effects beyond just work-related aspects, but become factors such as livelihoods, safety/environmental and food sovereignty. Relatedly, there is the territory as a valid category for understanding these processes, because it is embodied power relations and distinct territoriality. Finally, we also present reflections on the relationship of sugarcane capital, shaping the territory and the social, environmental and economic risks, which become gifts when deploying these large projects.
\end{abstract}

\footnotetext{
${ }^{1}$ Doutorando do Programa de Pós-Graduação em Geografia da Universidade Federal de Uberlândia, Bolsista CAPES, Membro do Núcleo de Estudos e Pesquisas Sobre Efeitos e Riscos nos Grandes Empreendimentos (NEPERGE).

${ }^{2}$ Professor do Programa de Pós-Graduação em Geografia da Universidade Federal de Uberlândia, Coordenador do Núcleo de Estudos e Pesquisas Sobre Efeitos e Riscos nos Grandes Empreendimentos (NEPERGE).
} 
Keywords: Developments Sugar Alcohol; Territory; Risks; Sugarcane.

\section{INTRODUÇÃO}

Vivemos em uma sociedade de riscos, em uma sociedade de ameaças resultantes da modernização e do progresso. Há algumas décadas esse assunto tem sido objeto de discussão em vários campos do conhecimento. Dessa forma, verifica-se os riscos que antecedem e se seguem na implantação dos grandes empreendimentos tornam-se uma necessidade, pois, é o capital o maior gerador de riscos as comunidades tradicionais.

É por meio desse pensamento que se concebe esse artigo, apresentando algumas inquietações, reflexões e debates realizados durante disciplina ministrada em Programa de Pós-Graduação.

Esse trabalho prioriza compreender como ocorre a formação do agronegócio canavieiro, destacando os riscos desse capital expropriador e os efeitos que se seguem, como resultados da exposição, de trabalhadores ou moradores de lugares onde foram implantados os projetos, ao risco.

Isso é importante, uma vez que a construção das territorialidades do capital em torno da cana-deaçúcar surge da atuação das relações de conflitualidade dos agentes envolvidos pelo capital existente no processo agrário e agrícola. Esses, por sua vez, nascem da contradição de suas interações e da necessidade de coexistência, mas na maioria recaem sobre a exclusão, formando estruturas territoriais temporariamente definidas e, em contrapartida, em constante processo de (re-des) territorialização, gerando riscos sociais, culturais, ambientais e políticos.

Metodologicamente as argumentações estão sustentadas em debates e revisões bibliográficas acerca do tema, expondo informações, reflexões e debates oriundos da utilização de diferentes publicações, tais como: livros, artigos, relatórios, dissertações e teses e, também, direcionamentos reflexivos da realidade do campo canavieiro.

Tendo essa premissa, apresentamos esse artigo estruturado basicamente em duas partes complementares. A primeira, que possui em sua problemática central o uma discussão sobre o entendimento que o capital é o agente promotor de riscos sociais. Tal reflexão traz à tona as transformações das realidades territoriais de forma a romper com as estruturas de vida e trabalho das comunidades tradicionais.

$\mathrm{Na}$ segunda parte, temos um momento reflexivo dos efeitos e resultados que se seguem em territórios onde o capital se apropria das dinâmicas locais, ou seja, as consequências da ocorrência do risco do capital canavieiro para as tradicionais estruturas vigentes. 


\section{Riscos e efeitos gerados na implantação de empreendimentos canavieiros}

\section{Os riscos para os grandes empreendimentos}

A priori faz-se necessário definir, teoricamente, o conceito de "risco". Portanto, é preciso entendêlo como um resultado de atividades sociais, o que por sua vez o materializa como uma possibilidade de efetivação de contraposições ao que está implantado, ou seja, o sentido de perigo ao que existe ou ao que foi construído pelas tarefas sociais.

Nesse direcionamento Veyret nos permite compreender o risco como "[...] uma construção social. A percepção que os atores têm de algo que representa um perigo para eles próprios, para os outros e seus bens, contribui para construir o risco que não depende unicamente de fatores ou processos objetivos" (VEYRET, 2007, p. 23).

Nesse mesmo entendimento, frente a importância do contexto histórico, torna-se uma necessidade compreender a historicidade na formação do que é o risco, pois ele permite gerar uma percepção sobre sua existência, tanto é que "o risco e a percepção que se tem dele não podem ser enfocados sem que se considere o contexto histórico que os produziu e, especialmente, as relações com os espaços geográficos, os modos de ocupação do território e as relações sociais características" (VEYRET, 2007, p. 26).

Em nosso entendimento, os riscos são criados pelos grandes empreendimentos, em especial quando do processo de sua implantação, são regidos por uma necessidade do capital em reproduzir seu modelo, tendo como direcionadores o aprimoramento e fortalecimento de grupos econômicos hegemônicos.

Nesse pensamento, da importância histórica do risco, também nos valemos de Beck (2006), ao estabelecer que para uma compreensão do que seja risco é necessário e, importante, requerer o entendimento de sua legitimação, já que fazer um acompanhamento dos riscos desde o passado, quando esses eram percebidos mediante aos sentidos humanos (visão, olfato, audição), até a sociedade atual, onde eles são globais, possibilita compreender o risco como fenômeno técnicocientífico. Ou seja, o risco na sociedade contemporânea está relacionado diretamente ao desenvolvimento tecnológico, que por sua vez são engendrados ao modelo econômico capitalista, que também é algo pertencente aos grandes projetos. 
Outro fator além do histórico é a perspectiva locacional, como mencionado por Veyret, isso se destaca nas "relações com o espaço geográfico" (2007, p. 26) com o risco. Nesse caráter territorial os riscos, logicamente, estão aliados ao seu território de ação, que por sua vez são em grande parte onipresentes para o indivíduo, para a sociedade e, em especial, aos sujeitos que tomam decisões, como os políticos.

Isso é confirmado por Veyret que destaca: "o risco é desde sempre indissociável da política: tomar as decisões concernentes à organização do território, à repartição dos bens, ao uso dos recursos, equivale, ao menos em parte, a fazer apostas sobre o futuro, a construir cenários que encerram sempre uma dose de riscos." (VEYRET, 2007, p. 29).

De acordo com November (2002), os riscos, em relação ao seu vínculo com o local, não importa a perspectiva na qual eles são abordados, eles se produzem dentro de um espaço geográfico, e mais precisamente, dentro de um território. Nessa medida o risco ou os riscos sempre serão territoriais. Portanto, também devemos compreender que além do aspecto histórico que impulsiona a formação dos riscos na contemporaneidade, esses são materializados em um território, gerando também espacialidades. Esse processo corrobora com o entendimento do risco como fenômeno dos Grandes Projetos de Investimentos por estarem aliados a um território de ação e de representação, como também, um território de expropriação e produção.

É nesse aspecto que a busca pelo entendimento da territorialização do processo de construção da sociedade e do agronegócio sucroalcooleiro é importante, já que também se utilizam dessa categoria e muitas vezes ultrapassam os limites territoriais, formando territórios regidos pelo capital, separando as relações do espaço de administração com do capital, criando seu território de interesse. Interesse esse que, em muitos casos, culminam com as rupturas de estruturas tradicionais, que estão presentes antes mesmo da articulação do capital.

Ainda segundo November, em outra obra, o risco é literalmente enraizado nos espaços por ser participante ativo das transformações territoriais, capaz de modificar áreas ao longo do tempo e, até mesmo, fazer-se parte integrante da paisagem que se estabelece.

[...] le risque est littérallement ancré dans les espaces. II s'agit donc, désormais, d'aborder le risque comme un élément participant activement, intrinsèquement, aux transformations territoriales, capable de marquer certains espaces sur le long terme et même d'être lisible dans le paysage. (NOVEMBER, 2006, p.294). ${ }^{3}$

\footnotetext{
${ }^{3}$ Tradução: [...] o risco é, literalmente, enraizada nos espaços. É, portanto, agora tratam do risco como um participante ativo transformações intrinsecamente territoriais, capaz de marcar algumas áreas ao longo do tempo e até mesmo ser legível em elemento da paisagem (NOVEMBER, 2006, p.294, tradução nossa).
} 
García-Tornel (1997) também considera esse entendimento e, portanto, essa categoria geográfica para compreender os riscos. Pois, o autor ao estabelecer o "território potencial de risco", como todo espaço que tem a possibilidade de sofrer o evento catastrófico, não importando o grau de intensidade coloca os grupos humanos em situações diversas de perigo, ou seja, em graus diferentes de vulnerabilidade, porque o território precisa ser representado como habitado, vivido e apropriado.

É importante ressaltar que, esses territórios e suas construções, principalmente, para os setores canavieiros, surgem a partir da atuação das relações e conflitos entre o capital e o trabalho, muitas vezes tradicionais, como também a partir dos conflitos dos próprios capitais de concorrência. Isso acarreta na formação de estruturas de territorialidades dos grandes empreendimentos sucroalcooleiros, os quais desenvolvem/reconstroem os territórios antes de identidades e relações da terra para com a terra, para relações capitalistas produtivas e desligadas às atividades sociais clássicas.

Partindo desses posicionamentos, definiremos que os riscos, materializados pelos grandes empreendimentos, nascem ou são gerados como uma ameaça ao que é produzido e mantido costumeiramente, rompendo com os modos de viver e tornando vulneráveis as sociedades tradicionais.

Desse modo, Veyret (2007) menciona que, esses riscos, são áleas às ameaças potenciais e/ou percepções que definem o comprometimento ao que está estabelecido, gerando assim uma vulnerabilidade. Nesse tocante, o autor define risco como "a representação de um perigo ou álea (reais ou supostos) que afetam os alvos e que constituem indicadores de vulnerabilidade" (VEYRET, 2007, p. 30).

A saber, vulnerabilidade deve ser compreendida como a fragilidade do sistema, processo ou atividade a áleas naturais ou tecnológicas. Veyret define em certo momento a vulnerabilidade como,

[...] estar fisicamente exposto a uma álea (natural ou outra), é apresentar certa fragilidade diante do sinistro [...]. É de igual modo, não ter em vista os meios disponíveis para enfrentar a crise que pode sobrevir [...]. Reduzir a vulnerabilidade não consiste em tentar reduzir a frequência da álea, o que é, em certos casos, totalmente impossível [...], mas em diminuir os efeitos possíveis da crise por meio do conhecimento dos processos e instalação de dispositivos adequados. (VEYRET, 2007, p. 43).

Ainda mais que, pessoas que vivem no meio de maior vulnerabilidade social, ou em outras palavras com uma fragilidade econômica, têm possibilidades maiores de sofrerem a 
materialização do risco. Nesse pensamento, haveria, então, uma espécie de diferenciação espacial do risco, porque esses não estão espalhados uniformemente sobre o território.

Isso é defendido por November, ao dizer que "populations qui vivent au milieu d'une plus grande vulnérabilité sociale [...] II existerait alors une sorte de différenciation spatiale des risques, du fait que les risques ne se répartissent pas partout, uniformément, sur le territoire" (NOVEMBER, 2006, p.290). ${ }^{4}$

Portanto, entendemos que os Grande Projetos de Investimentos (GPI), como o agroindustrial canavieiro, se mostram nesse processo como agentes causadores de riscos às sociedades estabelecidas, uma vez que se enquadram como riscos a manutenção dos territórios tradicionais. Enquanto que as populações tradicionais, ou melhor as sociedades de risco, se materializam como a representação da vulnerabilidade frente a chegada do capital.

Na fala de Veyret, ao analisar o "risco social" definimos que as sociedades tradicionais, estão sujeitas à "possibilidade de um acontecimento catastrófico para a coletividade humana, ou mais exatamente, como a probabilidade de ocorrência de um acontecimento cujas consequências poderiam ser nefastas para a sociedade" (VEYRET, 2007, p. 276-277), o que possibilitaria sua desterritorialização. Nessa perspectiva, temos os GPI, entre eles os empreendimentos canavieiros, como agentes que trazem riscos as comunidades, economias e setores locais clássicos.

Nessa perspectiva o risco deve ser compreendido como,

\begin{abstract}
Ameaças e incertezas pertencem às condições gerais de existência humana; a semântica do risco está relacionada especificamente com o processo de modernização, no qual adquirem maior significado as decisões, as incertezas e a probabilidade. Está relacionada à tematização no presente de perigos futuros, percebidos como resultado da civilização. (MOTTA, 2009, p.385)
\end{abstract}

Além de que os riscos atuais podem ser compreendidos como produtos do estágio industrial de produção e efeitos secundários sistemáticos dos processos de modernização, algo inerente aos GPI. Uma vez que esses são produtos históricos e resultantes de ações e omissões humanas, bem como expressão do desenvolvimento das forças produtivas e do período técnico-científicoinformacional, como definiu o período atual o geógrafo Milton Santos (1996).

Os riscos nesse processo são criados,

[...] por formas normativas sancionadas de atividades - como no caso dos jogos de azar ou esportes. Os mercados de investimentos representam facilmente o exemplo mais proeminente da vida social moderna. Todas as firmas de negócios [...] e todos os investidores, operam num ambiente onde cada um tem de prever

\footnotetext{
${ }^{4}$ Tradução: "populações que vivem no meio de maior vulnerabilidade social [...] existe uma espécie de diferenciação espacial do risco, porque os riscos não estão espalhados uniformemente sobre o território" (NOVEMBER, 2006, p.290, tradução nossa).
} 
os lances dos outros no sentido de maximizar os lucros. As incertezas envolvidas nas decisões de investimentos derivam em parte das dificuldades de antecipar eventos extrínsecos, tais como inovações tecnológicas, mas fazem também parte da natureza dos próprios mercados (GIDDENS, 1994, p. 130).

Dessa forma, os riscos nascem de políticas desenvolvimentistas dos projetos de investimentos e necessidades de mercado, mas afetam de maneira negativa, principalmente, as populações tradicionais locais, modificando seus modos de vida e de trabalho, em detrimento ao desenvolvimento do capital.

A expansão da atividade canavieira no Brasil, especificamente, no Pontal do Triângulo Mineiro, vem desencadeando a desterritorialização do campesinato e uma reterritorialização das estruturas produtivas. O grande capital, que consideramos como risco, se desloca de um lugar para outro, promove um processo de reterritorialização das estruturas que compõem o setor, como também das relações que configuravam o espaço desses territórios.

Todavia, mesmo que existam medidas de tratamento e mitigação do risco que é estabelecido, contribuindo ativamente para remodelar ações minimizadoras desses efeitos de ruptura nas tradições das populações, poderá haver resultados imprevisíveis. Pois, muitas vezes tentar sanar o risco que se estabelece em certos lugares, apesar de terem sido alvo de uma série de medidas, há possibilidades de serem gerados novos riscos às sociedades estabelecidas. Em outras palavras, a ação que deseja minimizar o risco contribui para destacar ou potencializar a presença de outros riscos.

Isso é destacado por November, o qual argumenta que

Il arrive en effet souvent que des risques collent à certains lieux, alors même qu'ils ont fait l'objet d'une série de mesures: en regardant de plus près, on s'aperçoit qu'il ne s'agit plus tout à fait des mêmes risques, comme si un transfert d'une catégorie de risque à une autre s'était produit. En d'autres mots, l'action qui conduit à minimiser un risque contribue, paradoxalement, à mettre en évidence la présence d'autres risques, ignorés ou du moins, non ciblés dans l'action précédente. (NOVEMBER, 2006, p.290). ${ }^{5}$

Em outras palavras, mesmo que o capital desenvolva ações para minimizar os problemas e rupturas dos modos de trabalho e viver das sociedades tradicionais, essas não se tornaram eficazes, uma vez que podem gerar novos riscos às comunidades já afetadas.

\footnotetext{
${ }^{5}$ Tradução: Acontece que muitas vezes o risco que ocorre em certos lugares, apesar de terem sido alvo de uma série de medidas: olhando mais de perto, vemos que ela não é mais que apenas feitos dos mesmos riscos, como se a transferência de uma categoria de risco tenha ocorrido. Em outras palavras, a ação que leva a minimizar o risco contribui, paradoxalmente, para destacar a presença de outros riscos, ignorado, ou pelo menos nãoalvo na ação anterior. (NOVEMBER, 2006, p.290, tradução nossa)
} 
A seguir, pensando nos possíveis resultados da dinâmica do capital canavieiro como risco que se estabelece às sociedades tradicionais, traremos um debate sobre os principais efeitos que esses empreendimentos criam, a fim de demonstrar seu caráter expropriador como uma finalidade de reprodução econômica.

\section{Efeitos da dinâmica do capital canavieiro}

Segundo estudiosos da dinâmica capitalista sucroalcooleira, o sistema de produção e mercado de cana-de-açúcar possui características peculiares que requerem planejamento de longo prazo, pois a cultura é de ciclo longo e sazonal, comercialização de curto prazo, perecibilidade por não ser um produto armazenável, com época certa para ser colhida e dificuldade para ser transportada a longas distâncias. O custo de transporte que inviabiliza longas distâncias restringindo seu mercado traz à tona a questão do apoderamento local da produção para esse setor, ou seja, apropriação de territórios para sua reprodução.

As especificidades de ativos envolvidos na transação da cana-de-açúcar são altas nos aspectos locacional (distância entre produtor e usina), físico (moendas de cana, tanques de armazenamento de álcool) e temporal (pericibilidade da cana e problemas de concentração do fornecimento de cana em determinadas épocas). Com estas características, as formas mais eficientes de transação da cana-de-açúcar entre produtores e usinas são (NEVES; WAACK; MARINO, 1998):

$\checkmark$ as usinas que são proprietárias das terras onde se plantam cana por meio de sua estrutura gerencial, sob o seu comando decisório, caracterizando integração vertical;

$\checkmark$ arrendamentos de terras de produtores por usinas, constituindo cana onde a usina tem controle total, mas não é proprietária dos ativos envolvidos na produção (terras);

$\checkmark$ produtores especializados: estes são os produtores de cana, especializados na atividade de produção (não realizam esmagamento), estando ligados "contratualmente" às usinas.

Essa estrutura de produção do setor sucroalcooleiro apresenta variação de região para região, mas geralmente as usinas não ficam totalmente dependentes de produtores especializados, atuam como detentoras de terras ou arrendatários, assim garantindo maior controle na produção, bem como o abastecimento de matéria-prima. 
A partir da observação dessa dinâmica, temos então a formação e reestruturação dos territórios dos empreendimentos sucroalcooleiros, os quais se apropriam de áreas para potencializar sua prática capitalista e reproduzir as bases necessárias para a sua autorregulação. Ou seja, o capital torna-se, então, uma possibilidade de riscos às comunidades tradicionais, já que suas representações clássicas não estão ligadas diretamente ao modelo pré-estabelecido.

Conforme Elias, os locais onde esses GPI, como o canavieiro, se instalam, são formados ou consolidados, como Regiões Produtivas Agrícolas (RPA) "novos espaços de fluxos rápidos inerentes às redes agroindustriais, nas quais as verticalidades têm predominância sobre as horizontalidades" (ELIAS, 2012, p. 155), que podem ser caracterizados pelos seguintes processos:

$\checkmark$ Intensa substituição dos sistemas técnicos agrícolas;

$\checkmark$ Significativa mudança das formas de uso e ocupação do espaço agrícola;

$\checkmark$ Forte substituição da produção de alimentos pela produção de commodities;

$\checkmark$ Substituição das vocações naturais pelas imposições econômicas;

$\checkmark$ Difusão de especializações produtivas.

Processos esses que podem ser compreendidos como alguns efeitos da materialização da apropriação dos territórios tradicionais pelo capital empreendedor, quando da materialização e efetivação de sua implantação, ou seja, a consumação do risco.

A autora destaca que esses RPA's são geradores de "produção de territórios especializados e corporativos inerentes dos diversos circuitos da economia agrária e agroindustrial, notadamente relacionados ao circuito superior do agronegócio globalizado" (ELIAS, 2012, p. 155).

Portanto, compreendemos que o agronegócio da cana-de-açúcar é uma materialização dessas Regiões Produtivas Agrícolas, pois as transformações agrícolas que a atividade canavieira ocasiona nos municípios em que se instalam são variadas, entre, outros efeitos temos a concentração de terras e a monocultura produtiva, tal como é apresentado pelo estudo da Comissão Pastoral da Terra Seção Nordeste.

A expansão do monocultivo da cana-de-açúcar no Brasil é devastadora como qualquer outro monocultivo. Esse modelo de agricultura que o País carrega desde o período colonial, que se baseia na concentração da terra e na produção agrícola para exportação, cai como uma luva para quem quer acumular capital à custa dos nossos recursos naturais, dos recursos públicos e do nosso povo. (PLÁCIO JR, 2008).

É importante lembrar que, temos também como efeitos no seguimento canavieiro, o crescimento de uma série de atividades comerciais e de serviços especializados, como destaca Elias. 
[...] a difusão do agronegócio não apenas amplia e reorganiza a produção material (agropecuária e industrial), como é determinante para a expansão quantitativa e qualitativa do comércio e dos serviços, especialmente dos ramos associados ao circuito superior da economia agrária. (ELIAS, 2011, p.159)

Como alguns outros resultados desse processo, criados para atender a demanda local que se instala temos: casas de comércio de implementos agrícolas especializados; escritórios de marketing e de consultoria contábil; instalação e acesso a centros de pesquisa biotecnológica; instalação de empresas de assistência técnica e de transportes de cargas; criação de cursos técnicos de níveis médio e superior voltados ao agronegócio; entre outros.

Uma questão importante, mas que ainda não foi possível precisar empiricamente, porém constatada nas argumentações e reflexões analisadas, são os efeitos sobre as áreas de cultivos de alimentos e mesmo a concentração fundiária. Lembrando que a compra de terras e o arrendamento são fortes indícios desse processo nos municípios da região do Pontal do Triângulo Mineiro.

Nessa questão temos o território sujeitando-se a uma nova forma de produzir, onde o monopólio das terras, através da propriedade privada e/ou do arrendamento, passa a desempenhar um papel preponderante de deterioração da renda fundiária, que é a lógica da racionalidade econômica capitalista no âmbito da agricultura de base empresarial - empregada pelos empreendimentos sucroalcooleiros.

É necessário compreender que esta concentração fundiária é inerente ao modelo de operação do agronegócio canavieiro, o que representa dizer que o capital produtivo só investe no campo para remunerar o seu capital investido, ou melhor, reproduzi-lo de forma ampliada, ao contrário do camponês, que pertence às comunidades tradicionais, que cultivam na terra para retirar dela a sua subsistência e a de suas famílias.

Essa constatação engendra uma discussão a respeito da concentração fundiária, como também possibilita o debate que envolve a dualidade existente entre a expansão da monocultura canavieira e a produção dos alimentos para o mercado interno.

Portanto, novos efeitos são gerados nessa realidade produtiva capitalista. Para conhecimento, foi possível definir três principais universos de efeitos reais dos empreendimentos sucroalcooleiros, sendo eles: 1) Na produção de alimento: deslocamento e expropriação; 2) Na relação de trabalho: condições e sobrevivência; 3) Ao Ambiente: recursos e sustentabilidade. Ressaltando que tais efeitos englobam territorialidades, dimensões de sobrevivência e conflitos de capital. 
Assim, entendemos que o território agrário e clássico local são drasticamente afetados pelo capital do GPI. Os resultados mais concretos e empiricamente verificáveis são o predomínio de uma nova cultura na paisagem, o que significa a destruição de usos, que prevaleceram no período anterior à implementação da atividade canavieira.

Não é difícil de constatar que esta substituição foi orientada pela rentabilidade, posto que os cultivos alimentares, via de regra, apresentam margem de lucro incompatíveis com as taxas médias de lucro perseguidas pelo agronegócio, o que as tornam momentaneamente inviáveis para a agricultura de base empresarial.

Também não se pode esquecer o efeito que a expansão da lavoura canavieira produz no aumento dos custos de produção de várias culturas, as quais estão no entorno da sua expansão, refletidos não somente no aumento do valor do aluguel da terra, mas também na regulação dos preços do frete, da força-de-trabalho e, consecutivo, aumento do valor desta mercadoria. Assim como o aumento nos custos relativos a hora trabalhada pelas máquinas, que passam a operar tendo como marco regulatório os valores comparativos pagos pelos empreendimentos canavieiros, expropriando a produção e realidade de vida camponesa local.

Trata-se na verdade de uma vulnerabilidade das sociedades estabelecidas, com uma conversão destes municípios, principalmente, os menores, em apenas base territorial da produção sucroalcooleira, da qual o agronegócio passa a exercer um domínio sobre as terras e sobre os trabalhadores. O Estado na sua representação local cria e recria as condições necessárias para a reprodução ampliada do capital que territorializa estas porções espaciais.

Isto porque, apesar das plantações e/ou da agroindústria se localizarem normalmente em municípios de pequeno porte, os centros de tomada de decisões estão fora das suas fronteiras, estando as sedes sociais dessas agroindústrias, geralmente, localizadas em outros estados do país, excetuando as agroindustriais da região.

Nessa premissa Souza destaca que,

[...] a canavicultura de base empresarial é uma atividade que concentra terras tanto do ponto de vista quantitativo, quanto espacial, fato que justifica sua territorialização de forma concentrada no entorno da agroindústria, por razões de ordem da racionalidade econômica capitalista. [...] Ora, esta concentração espacial, aliada a subordinação massiva de todos os fatores de produção existentes no local, dificulta a diversidade econômica (SOUZA, 2010, p.194).

Como força produtiva local, os empreendimentos sucroalcooleiros, após desencadearem a apropriação dos territórios produtivos culturais locais, geram e, automaticamente, recria a 
subordinação local para com este processo de exploração, o que por vezes pode significar a única possibilidade de setor de trabalho para sustentar sua família.

Assim, sem acesso à terra, para o trabalho e vida, essas massas de trabalhadores expropriados, agora alojadas nas cidades, passam a disputar as escassas vagas disponíveis em serviços urbanos. Somando a isso o fato de não terem, a qualificação necessária para tais funções, o que os obriga a se subjugarem ao trabalho disponível, quando existem, sob quaisquer condições.

São gerados nesse caminho muitos problemas ditos urbanos, mas que estão intimamente ligados ao que ocorre no rural. Como mencionado à agricultura agroindustrializada gera, consequentemente, concentração da terra e exclusão territorial e, ao mesmo tempo, com a formação de bairros periféricos nas cidades, muitas vezes, justamente por migrantes do espaço rural. O que por vezes nos cabe entender que o desenvolvimento regional/local deveria ser uma prática para regular os efeitos do agronegócio canavieiro, por exemplo.

A cerca do desenvolvimento valemos dos direcionamentos de Saquet e Sposito, ao mencionar que:

O desenvolvimento, [...] está ligado tanto à exploração das potencialidades locais para seu alcance social quanto à conservação dos recursos naturais. Por isso, pensa-lo requer: a) valorizar os enraizamentos social, econômico e cultural da sociedade local, indo além de análises estritamente econômicas; b) priorizar as instituições públicas locais, a autonomia das finanças públicas e o investimento de excedentes em setores sociais estratégicos. Em outras palavras, pensar o desenvolvimento local requer não somente olhar para a ciência econômica (agregação de valor), mas também procurar contribuir para a melhoria da qualidade de vida das pessoas [...]. (SAQUET; SPOSITO, 2008, p. 22).

Assim sendo, ressalta-se que o desenvolvimento local deve ser visto como um processo histórico, relacional e territorial, portanto, caracterizado pela apropriação e construção dos territórios por meio das identidades culturais, do poder e das redes locais.

Nessa perspectiva temos nos empreendimentos sucroalcooleiros que se instalam, uma contradição produtiva e expropriatória do campo, a mercê dos direcionamentos e subjugações do desenvolvimento pelo e para o capital, que por sua vez continuam a se ampliar, já que em seu entorno ocorre uma elevação da apropriação do território, sem desenvolvimento voltado aos subjugados.

É possível perceber, de acordo com Houtart, que o setor sucroalcooleiro, voltado atualmente para a geração de energia, tem expropriado esses camponeses de suas terras, ao mencionar que:

La agro energia - presentada como una solución técnica-, es la solución del capital contra la naturaleza, contra los trabajadores y por la eliminación del 
Evidenciando a questão da contradição gerada nos sistemas produtivos desses grandes empreendimentos remetemos a Silva,

[...] um processo amplamente contraditório se instaura no lugar. Produzimos o que não consumimos e consumimos o que não produzimos. Parece irracional e, de fato, o é, principalmente, porque as cifras da fome se comparadas às cifras da produção nos fazem parecer inúteis. As modernas tecnologias que fazem crescer, enormemente, as produções também elucidam o disparate entre aqueles que detêm o poder e os que acabam à sua mercê (SILVA, 2007, p.19).

Alguns poderiam dizer que esse processo trouxe o desenvolvimento econômico à realidade local, mas temos que entender, apoiado na questão da realidade de vida das comunidades tradicionais, as quais antes de excluídas, expropriadas pelo capital da cana-de-açúcar, têm valores, identidades e pertencimentos ao território. Sobre isso Silva relata que,

As transformações no campo e na cidade com objetivo de produzir novos produtos acarretam drásticas transformações do simbólico, algo, talvez, importante apenas no local e sem sentido fora do seu contexto. Algo muitas vezes rotulado pelo outro como atraso de vida, primitivismo, necessitado de se modernizar. Mas algo que, no interior da sociedade que o vive, representa a sua identidade (SILVA, 2007, p.19).

Portanto, o território também imaterial é (re-des) construído com as dinâmicas de implantação e ampliação dos empreendimentos sucroalcooleiros. Todavia, salientamos que estes camponeses, apesar de desterritorializados, estão imbuídos dos seus valores tradicionais resistindo com sua presença de maneira heterogênea, em parte do território, ao residir na manifestação do campo no interior da cidade e/ou até mesmo em unidades camponesas ilhadas nos mares de canas.

\section{CONSIDERAÇÕES FINAIS}

Os riscos, há algumas décadas, é um assunto que tem sido objeto de discussão em vários campos do conhecimento, com a intenção de verificar os riscos que antecedem e os efeitos que se seguem na implantação dos grandes empreendimentos, torna-se cada vez um desafio, mas na verdade uma necessidade, pois, o capital é o maior gerador de riscos às comunidades tradicionais.

\footnotetext{
${ }^{6}$ Tradução: A agroenergia é apresentada como uma solução técnica, mas é a solução do capital contra a natureza, contra os trabalhadores e a eliminação do pequeno produtor camponês. Nos últimos 20 anos, 6 milhões de camponeses foram expulsos de suas terras no Brasil (HOUTART, 2009, p. 45, tradução nossa)
} 
Em nosso estudo percebemos que a (re) construção das territorialidades do capital, em torno da cana-de-açúcar, surgem da conflitualidade dos agentes envolvidos, de um lado o capital e do outro as populações afetadas, mas que na maioria recaem sobre processos de exclusão, formação de novas estruturas territoriais, gerando riscos sociais, culturais, ambientais e políticos.

Assim, entendemos que as comunidades tradicionais são sociedade de risco, que estão ameaçadas pelo processo e modelo de modernização implementado pelo capital, que tem como discurso principal o progresso, mas que na verdade utilizam desses territórios para sua reprodução.

Percebemos que o risco, na sociedade contemporânea, está relacionado diretamente ao desenvolvimento tecnológico, que são engendrados ao modelo econômico capitalista de reprodução, que por sua vez é algo pertencente aos grandes projetos. Esses processos formam territórios regidos pelo capital, separando as relações do espaço de administração com do capital, criando seu território de interesse. Interesse que, em muitos casos, culminam com a rupturas de estruturas tradicionais, que estão presentes antes mesmo da articulação do capital.

No setor canavieiro constatamos que os grandes projetos de investimentos do agronegócio, quando passam de um risco para a efetivação/materialização, esses normalmente se instalam nas Regiões Produtivas Agrícolas, gerando diversos efeitos como a substituição dos sistemas técnicos agrícolas tradicionais, mudança das formas de uso e ocupação das áreas agrícolas, substituição da produção de alimentos pela produção de commodities, ruptura das vocações naturais produtivas e especializações produtivas.

A partir desse direcionamento foi possível construir três principais universos de efeitos reais dos empreendimentos sucroalcooleiros. O primeiro que é definido pela produção de alimento o que ocasiona o deslocamento e expropriação das atividades tradicionais, o segundo que pertence a esfera das relações de trabalho, ligados as condições e modos de sobrevivência das populações atingidas, e por fim, o terceiro universo que destaca a vertente do Meio Ambiente, englobando os recursos/bens naturais e sustentabilidade. Atentamos que todos esses efeitos englobam territorialidades, dimensões de sobrevivência e conflitos de capital.

Trata-se na verdade de uma vulnerabilidade das sociedades estabelecidas, com uma conversão dos municípios atingidos em apenas base territorial da produção sucroalcooleira, da qual o agronegócio passa a exercer um domínio sobre as terras, sobre os trabalhadores e rompimentos das estruturas tradicionais, que em alguns casos tentam se manter, resistindo ao processo expropriador do capital. 
AGRADECIMENTO

Agradecimento à CAPES, pela concessão de bolsa de estudo.

\section{REFERÊNCIAS}

BECK, Ulrich. La sociedad del riesgo: hacia una nueva modernidad. Barcelona: Paidós, 1986, (2006).

ELIAS, Denise. Agronegócio e novas regionalizações no Brasil. Revista Brasileira de Estudos Urbanos e Regionais, Local de publicação (editar no plugin de tradução o arquivo da citação $\begin{array}{lllll}\text { ABNT), } & \text { 13, jun. } 2012 . & \text { Disponível }\end{array}$ <http://www.anpur.org.br/revista/rbeur/index.php/rbeur/article/view/400>. Acesso em: 01 Dez. 2013.

GARCÍA-TORNEL, Francisco Calvo. Algunas cuestiones sobre Geografía de los Riesgos. Scripta Nova. Revista Electrónica de Geografía y Ciencias Sociales, Barcelona, n. 10, 1997. Disponível em: http://www.ub.edu/geocrit/sn-10.htm. Acesso em: 20 maio 2014

GIDDENS, Anthony. A transformação da intimidade. São Paulo: Ed. Unesp, 1994.

GONÇALVES, J. S. A eficiência setorial de longo prazo e a concentração da terra e da renda no complexo sucroalcooleiro paulista. Agricultura em São Paulo, São Paulo: v.2, n.38, p.69-115, maio 1991. Disponível em:<www.iea.sp.gov.br/out/iagrisp.htm>. Acesso em: 03 fev. 2013.

HAESBAERT, R. O mito da desterritorialização: do "fim dos territórios" à multiterritorialidade. Rio de Janeiro: Bertrand Brasil, 2004a. 400 p.

HAESBAERT, Rogério. Des-caminhos e perspectivas do território. In: RIBAS, A. D.; SPOSITO, E. S.; SAQUET, M. A. (Org.). Território e Desenvolvimento: diferentes abordagens. Francisco Beltrão: UNIOESTE, 2004b. 171 p. p. 87-120.

HOUTART, François. La Agroenergia: solución para el clima o salida de la crisis para el capital. Ruth Casa editorial La Habana. Editorial de Ciencias Sociales, 2009.

KAgEYAMA, A.; SILVA, J. G. A Dinâmica da Agricultura Brasileira: Do Complexo Rural aos Complexos Agroindustriais. Campinas: 1988 
MARTINS, J. S. A chegada do Estranho. São Paulo: Hucitec, 1993.

MORENO, Camila. Agroenergia X Soberania Alimentar: a Questão Agrária do século XXI. Dinheiro Rural, ano III, número 25, pág. 76-77, novembro de 2006.

MOTTA, Renata. Sociologia de risco: globalizando a modernidade Reflexiva. Sociologias, Porto Alegre, v. 11 , n. 22, jul./dez. 2009, p. 384-396. Disponível em: http://seer.ufrgs.br/index.php/sociologias/article/view/9653/5524,. Acesso em: 22 maio 2014

MÜLLER, G. Agricultura e industrialização do campo no Brasil. Revista de Economia Política. São Paulo: 2(2):47-77, abril-junho de 1982.

NEVES, M. F.; WAACK, R. S.; MARINO, M. K. O sistema agroindustrial de cana-de-açúcar: caracterização das transações entre empresas de insumos, produtores de cana e usinas. In: Congresso Brasileiro de Economia e Sociologia Rural, 36, 1998, Poços de Caldas: Anais. Brasília, DF: SOBER, p. 559-572. 1998.

NOVEMBER, Valérie. Le risque comme objet géographique. Chantiers de géographie du Québec. Quebec, v. 50, n. 141, Dez. 2006, p. 289-296. Disponível em: http://espri.epfl.ch/webdav/site/espri/shared/pdf/Le\%20risque\%20comme\%20objet\%20g\%C3\%A 9ographique.pdf. Acesso em: 22 maio 2014

NOVEMBER, Valerie. Les Territoires du risque: le risque comme objet de refléxion géographique. Berna: Lang, 2002. Disponível em: http://developpementdurable.revues.org/1319?lang=en . Acesso em: 22 maio 2014

OLIVEIRA, A. M. S. A relação capital-trabalho na agroindústria sucroalcooleira paulista e a intensificação do corte mecanizado: gestão do trabalho e certificação ambiental. Presidente Prudente. 2003. 226 f. Dissertação (Mestrado em Geografia)-Universidade Estadual Paulista, Presidente Prudente: 2003.

OLIVEIRA, A. U. Os Agrocombustíveis e a Produção de Alimentos. In: SIMONETTI, Mirian Claudia Lourenção. (Org.). A (in) sustentabilidade do desenvolvimento: meio ambiente, agronegócio e movimentos sociais. 1a. ed. São Paulo/Marilia: CulturaAcadêmica/Oficina Universitária, 2011, v. 1, p. $159-180$. 
ORTEGA, A. C. Territórios deprimidos: desafios para as políticas de desenvolvimento rural. Campinas: Alínea/EDUFU: Uberlândia: 2008. 244 p.

PINTO, Mairun Junqueira Alves. Investimentos Diretos Estrangeiros no Setor Sucroenergético. 2011. 171 f. Dissertação (Mestrado em Administração das Organizações) - Faculdade de Economia, Administração e Contabilidade de Ribeirão Preto, 2011.

PIQUET, R.; RIBEIRO, A. C. T. (Org.). Brasil, território da desigualdade: descaminhos da modernização. Rio de Janeiro: Jorge Zahar, 1991. 181p.

PLÁCIDO JR. J. Expansão do monocultivo de cana no Brasil. CPT PE, Recife, jan. 2008. Entrevista $\begin{array}{lllll}\text { concedida } & \text { a } & \text { Michelle } & \text { Amaral. } & \text { Disponível }\end{array}$ <http://www.cptpe.org.br/modules.php?name=News\&file=article\&sid=1823>. Acesso em: 03 fev. 2013.

RAFFESTIN, C. Por uma Geografia do poder. Tradução de Maria Cecília França. São Paulo: Ática, 1993. $270 \mathrm{p}$.

RIBAS, A. D.; SPOSITO, E. S.; SAQUET, M. A. (Org.). Território e desenvolvimento: diferentes abordagens. Francisco Beltrão: UNIOESTE, 2004. 171 p. p.121-147.

SANTOS, Milton. A natureza do espaço: técnica e tempo, razão e emoção. São Paulo: Hucitec, 1996.

SAQUET, M. A.; SPOSITO, E. S. Território, Territorialidade e Desenvolvimento: Diferentes perspectivas no nível internacional e no Brasil. In: ALVES, A.F; CARRIJO, B. R; CANDIOTTO, L. Z. P. (Orgs.). Desenvolvimento territorial e agroecologia. 1a Ed. São Paulo: Expressão Popular, 2008, pp. 15-32.

SAQUET, Marcos Aurélio. Abordagens e concepções de território. São Paulo: Expressão Popular, 2007.

SAQUET, Marcos Aurélio. Por uma abordagem territorial. In: SAQUET, M. A. \& SPOSITO, E. S. (Orgs.). Territórios e territorialidades: Teorias, processos e conflitos. 1aㅡ ed. São Paulo: Expressão Popular, 2009. PP. 73-94. 
SILVA, José Graziano. A nova dinâmica da agricultura brasileira. Campinas: Ed. Unicamp, 1996. $217 p$.

SILVA, V. P. Grandes projetos e transformação no sentido de lugar. Caminhos de Geografia. Uberlândia. v. 8, n. 21, Jun/2007. p. 18 - 28.

SOUZA, M. A. A dinâmica geográfica da territorialização do agronegócio sucroalcooleiro no Estado do Paraná: notas para um debate. Caderno Prudentino de Geografia. n.32, vol.1, p.177201, jan/jun. 2010.

SPOSITO, E. S. Sobre o conceito de território: um exercício metodológico para a leitura da formação territorial do sudoeste do Paraná. In: RIBAS, A. D.; SPOSITO, E. S.; SAQUET, M. A. (Org.). Território e desenvolvimento: diferentes abordagens. Francisco Beltrão: UNIOESTE, 2004. 171 p. p. 15-36.

VEYRET, Yvette. Os riscos: o homem como agressor e vítima do meio ambiente. São Paulo: Contexto, 2007. 319p.

Artigo submetido em: 22/07/2014

Artigo aceito em: 18/09/2014 